\title{
In Lupus Erythematosus the Deposition of Immune Complexes in Tissues Is Mediated via Nuclear Histones Released by Neutrophils Nets but the Main Damage to Hosts Tissues Is Caused by the Plethora of Toxic Pro Inflammatory Agents Released by Activated Neutrophils-A Working Hypothesis
}

\author{
Isaac Ginsburg \\ Institute for dental Sciences faculty of Dental Medicine Hebrew University, Hadassah Medical Center, Jerusalem, Israel \\ Email: ginsburg@mail.huji.ac.il
}

\begin{abstract}
How to cite this paper: Ginsburg, I. (2020) In Lupus Erythematosus the Deposition of Immune Complexes in Tissues Is Mediated via Nuclear Histones Released by Neutrophils Nets but the Main Damage to Hosts Tissues Is Caused by the Plethora of Toxic Pro Inflammatory Agents Released by Activated Neutrophils-A Working Hypothesis. Open Journal of Rheumatology and Autoimmune Diseases, 10, 79-87. https://doi.org/10.4236/ojra.2020.102010
\end{abstract}

Received: February 10, 2020

Accepted: May 26, 2020

Published: May 29, 2020

Copyright $\odot 2020$ by author(s) and Scientific Research Publishing Inc. This work is licensed under the Creative Commons Attribution International License (CC BY 4.0).

http://creativecommons.org/licenses/by/4.0/

\section{Abstract}

The present study offers a novel approach that may explain the mechanisms of pathogenicity of the auto immune destructive disorder, Lupus Erythematosus. It is proposed that deposition of immune complexes and complement components in tissue is mediated by highly cationic histones released from neutrophils nets the phenomenon of netosis. Histones act a potent opsonic factor similar to antibodies which interact by strong electrostatic forces with negatively-charged domains in immune complexes and complements facilitating their deposition and also their internalization by hosts' cells. However, the main cause of cell and tissue damage in Lupus is inflicted by the plethora of toxic pro inflammatory agonists released by neutrophils and by macrophages recruited to inflamed tissues by cytokines. The melioration of tissue damage may be initiated by highly anionic heparins, which neutralizes histones' action if also combined with steroids, colchicin and methtorxate as well as by other agents which retard leukocytes migration and functions.

\section{Keywords}

Auto Immune Destructive Disorder, Lupus Erythematosus 


\section{Introduction}

Systemic lupus erythematosus (SLE) is a chronic autoimmune disorder of still an unknown cause that can affect virtually any organ of the body. Lupus can affect men and women of any race or age. One in 2000 people in the United States has lupus. Specific areas of the body that may be affected during the course of SLE include: the skin, joints, muscles and kidneys. The blood may also be affected during the course of lupus, resulting in low red blood cell count, low white blood cell count and low platelet counts. Patients show variable clinical features ranging from mild joint and skin involvement to life-threatening renal, hematologic, or central nervous system involvements. The diagnosis of SLE is generally based on clinical and laboratory findings. Although the exact causes of systemic SLE still remain unclear, genetic, hormonal, and environmental factors may contribute to the development of the disease [1]. As of today, no reasonable explanations have been offered to explain the mechanisms by which immune complexes and complement components are deposited in tissues and how this process can be prevented.

\section{A Working Hypothesis}

In the present short communication, it is argued that SLE, a multifactorial auto immune inflammatory disorder develops when circulating immune complexes and complement components are deposited in various tissues of patients. This process is accompanied by the recruitment of huge numbers neutrophils (PMNs) recruited by cytokines [2]. Upon activation at the tissue sites, PMNs can be activated to release into the surrounding media a plethora of toxic pro inflammatory agonists [3] [4] which cam act in synergy to injure cells and tissues.

We hereby suggest the mechanisms by which immune complexes are deposited in tissues of SLE patients.

It is proposed that highly cationic poly electrolytes such as histones, LL37, defensins and elastase released from activated PMNs nets (traps) [5] [6] [7] [8] (the phenomenon of netosis), may serve as key factors in Lupus pathogenicity. It is usually agreed that these catonic agents may mainly act in vivo as bactericidal and cytocidal agents. We hereby propose that such released poycations may also function as potent opsonins (opsonic agents), possessing properties similar to antibodies [9]. The poly cationic opsonins have now the ability to bind by strong electrostatic forces to negatively-charged domains in circulating immune complexes and in complement components facilitating their deposition and also their internalization by host cells.

Actually, this novel suggestion, originate from our previous observations showing that if suspensions of group A hemolytic streptococci, Candida albicans [10], and even whole isolated cell nuclei [11] which had been pre coated (opsonized) by the highly cationic histones, could effectively bind to and also undergo endocytosis not only by professional phagocytes such as PMNs and macrophages but, also by endothelial cells, fibroblast and even by epithelial cells. 
However as has already been proposed in many earlier publications [3] [4] [12]-[30], the main cause of cell and tissue damage seen in inflammatory post inflammatory a most probably also in autoimmune disorders, is eventually caused by a tight synergism induced among the plethora of secreted pro inflammatory agents released by activated PMNs and by macrophages. Upon activation in the tissues, these cells are capable of releasing into the surrounding media: reactive oxygen and nitrogen species, $\mathrm{HOCl}$, highly cationic histones, LL37, elastase, defensins, toxic membrane-damaging phospholipase A2, and lysophosphatides, fatty acids and several acid hydrolases, which can act synergistically to injure cells and tissues These studied where summarized and discussed in detail in [3] [4].

\section{The Possible Role of Infections and the Activation of the Bacteriolysis Phenomenon in Lupus Pathogenicity}

During sporadic infections in lupus patients, microbial infections might also occur. Several microbial species may undergo bacteriolysis due to the activation of their endogenous autolytic wall enzymes (muramidases) [30]. This phenomenon, may be induced in vivo either by the poly cation lysozyme released from PMNs [25] or also by certain antibiotics [30]. Bacteriolysis can also release into the surrounding media toxic lipoteichoic acid [31] and peptidoglycan from Gram positives and Gram negatives and also toxic endotoxins from Gram negatives [32]. However, microbial non-bio degradable cell wall fragments released following bacteriolysis, may also be lodged for long periods in macrophages in the joints, causing chronic relapsing arthritis [33] [34] [35] [36]. This may be identified either by electron microcopy, or by measuring, by HPLC the presence of muramic acid, the integral component of the microbial peptidoglycan [36]. Also, Th1 cytokines generated [37], can constantly stimulate the recruitment, migration and localization in host tissues of additional PMNs which upon activation in the inflamed cites, may further create waves of toxic pro inflammatory agonists. It is also of importance, at this time, to note that the mechanisms of tissue damage in inflammation and in post inflammatory episodes induced by activated PMNs and possibly also in in auto immune episodes, may be strikingly similar to those seen in infections caused by group A hemolytic streptococci [38]. In both cases, a typical synergy among secreted pro inflammatory agonists is involved in cell and tissue damage.

\section{Can Highly Anionic Heparins and Heparinoids Prevent Tissue Damage in SLE?}

To prevent the binding, deposition, and endocytosis of immune complexes and complement components in tissues mediated by the action of cationic opsonins [9] it may be reasonable to consider the administration to SLE patients of the highly negatively-charged anti-coagulant heparin [39] and heparinoids [40] [41] since these common drug, might be able to strongly neutralize the opsonic power of the poly cationic histones and can thus prevent the deposition of immune 
complexes and complement components in tissues. and thus to delay the onset auto immune nephritis [40]. An attention has also been focused on the role of electrostatic charges in the pathogenesis of immune complex-mediated tissue injury. These authors have examined the ability of cationic histone and of the histone mimic, poly L-arginine, to modulate acute immune complex-mediated tissue injury [41].

\section{Drugs Recommended for Use to Treat Lupus Patients}

In addition to the anionic heparins [39] [40] [41], a use of combinations among aspirin, corticosteroids, methotrexate, colchicine, cyclophosphamide and additional agents capable of suppressing PMNs chemotaxis is advised [42] [43]. However, since oxidants and proteinases are considered major cell and tissue damaging agents as described in many studies [3] [4] [12]-[30], the use of low molecular weight anti-oxidants, ascorbate, $\mathrm{N}$-acetyl cysteine, glutathione and also anti oxidants from plants such as green and colored vegetables, citruses, tea, coffee and cranberries, all rich in anti oxidants, when combined with the anti-proteinase inhibitor aprotinin, might be effective to ameliorate arthritis [42]. Also, the membrane-damaging phospholipase A2 and lysophosphatides generated by PMNs could be inhibited by lecithin [42] and anti-TNF alpha agents may also be effective to ameliorate cell and tissue damage in Lupus patients.

A huge number of other old and novel drugs have been recently tried to treat SLE [42]. These include: glucocorticoids, nonsteroidal anti-inflammatory drugs (NSAIDs), Hydroxychloroquine (HCQ), Immuno suppressants whlicl include: azathioprine (AZA), mycophenolate mofetil (MMF), and cyclophosphamide $(\mathrm{CYC}$,$) the biological: rituximab and belimumab, both monoclonal antibodies.$ Rituximab targets B cells and is used to treat renal and CNS presentations of SLE. This agent is recognized as a second- or third-line agent for active disease. Belimumab targets the B-cell activating factor B-lymphocyte stimulator (BLyS), Belimumab is approved for use in active disease in conjunction with standard therapies including GCs, antimalarials, and AZA. It is not, however, recommended for concomitant use with CYC or with other biologics. It is the most recent FDA-approved drug for SLE; prior to belimumab's approval in 2011, there had been no novel SLE-approved drugs for more than 50 years.

Unfortunately, as of today, despite the development of novel new drugs proposed to treat SLE, no real effective common agents are available to heal the SLE symptoms and also prevent the destructive pathology seen in this autoimmune disorder, SLE. However, as reported in our current article, the anti-coagulant heparin might be an excellent drug since it may be able to neurlize poly cations such as histone, LL37, elastase and additional toxic poly cations suggested to be main agents in SLE pathogenicity.

\section{Summary and Conclusions}

We hereby offer an overview of overlapping and successional steps which may 
help to explain the mechanisms and development of the auto immune disorder, SLE.

These involve:

1) Generation of autoimmune complexes and the activation of the complement cascades.

2) The release from PMNs nets (netosis) of highly cationic toxic histones and formation of citrullinated histones.

3) Cationic Histone from PMMs nets may also function as potent opsonic agents which possess properties similar to antibodies, may interact with and also bind by strong electrostatic forces to negatively-charged domains in immune complexes and complement components, facilitating their binding, deposition and possibly also their internalization by tissue cells.

4) PMNs and Macrophages migrating to the tissue sites undergo activation to release into the surrounding media, a plethora of toxic pro inflammatory agonists. These mainly include: cationic peptides, oxidants, proteinases, membrane-perforators phospholipases, fatty acids which may all act synergistically to injure cells, in synovia and also in cartilage.

5) Protection against the progression of tissue damage in SLE, might be provided by highly anionic heparin and heparinoids, which can neutralize the toxicity of poly the opsonins poly cations.

6) Sporadic infections, which may accompany SLE, may lead to bacteriolysis and to the release of microbial cell wall components which may lodge in macrophages in the joints, to induce chronic relapsing arthritis.

7) Toxic oxidants and proteinases released by PMNs and by macrophages may be controlled to some extent by multi drug strategies and by the low molecular weight anti-oxidants: glutathione, ascorbate, $\mathrm{N}$-acetyl cysteine as well as by certain plant polyphenols, anti proteinase, aprotinin, by PLA2 inhibitors and also by anti oxidant agents preset in green vegetables and ripe colored fruits.

8) Common drugs which may be efficient to treat and ameliorate symptoms of SLE patients may include: Aspirin, corticosteroids, methotrexate and colchicine and additional novel drugs.

9) Can we learn from the pathogenesis of group A hemolytic streptococcal infections how tissues are injured in post inflammatory sequelae. This analogy may also help to explain the mechanisms of cell damage in SLE and possibly also in the auto immune phenomena.

10) Taken together, we may now also conclude that similar mechanisms of tissue damage, may also occur in the auto immune disorders ulcerative colitis, chromes disease, nephritis, rheumatic fever, rheumatoid arthritis and possibly also in additional auto immune disorders.

\section{Conflicts of Interest}

The author declares no conflicts of interest regarding the publication of this paper. 


\section{References}

[1] Maidhof, W. and Hilas, O. (2012) Lupus: An Overview of the Disease and Management Options. Pharmacy and Therapeutics, 37, 240.

[2] Kaplan, M.J. (2013) Role of Neutrophils in Systemic Autoimmune Diseases. Arthritis Research \& Therapy, 15, 219. https://doi.org/10.1186/ar4325

[3] Ginsburg, I. (1998) Could Synergistic Interactions among Reactive Oxygen Species, Proteinases, Membrane-Perforating Enzymes, Hydrolases, Microbial Hemolysins and Cytokines Be the Main Cause of Tissue Damage in Infectious and Inflammatory Conditions? Medical Hypotheses, 51, 337-346. https://doi.org/10.1016/S0306-9877(98)90059-7

[4] Ginsburg, I. and Kohen, R. (1995) Invited Review: Cell Damage in Inflammatory and Infectious Sites Might Involve a Coordinated "Cross-Talk" among Oxidants, Microbial Haemolysins and Ampiphiles, Cationic Proteins, Phospholipases, Fatty Acids, Proteinases and Cytokines: An Overview. Free Radical Research, 22, 489-517. https://doi.org/10.3109/10715769509150323

[5] Gupta, S. and Kaplan, M.J. (2016) The Role of Neutrophils and NETosis in Autoimmune and Renal Diseases. Nature Reviews Nephrology, 12, 402. https://doi.org/10.1038/nrneph.2016.71

[6] Wright, H.L., Moots, R.J., Bucknall, R.C. and Edwards, S.W. (2010) Neutrophil Function in Inflammation and Inflammatory Diseases. Rheumatology, 49, 1618-1631. https://doi.org/10.1093/rheumatology/keq045

[7] Brinkmann, V. and Zychlinsky, A. (2012) Neutrophil Extracellular Traps: Is Immunity the Second Function of Chromatin? Journal of Cell Biology, 198, 773-783. https://doi.org/10.1083/jcb.201203170

[8] Yang, H., Biermann, M.H., Brauner, J.M., Liu, Y., Zhao, Y. and Herrmann, M. (2016) New Insights into Neutrophil Extracellular Traps: Mechanisms of Formation and Role in Inflammation. Frontiers in Immunology, 7, 302.

https://doi.org/10.3389/fimmu.2016.00302

[9] Ginsburg, I. (1987) Cationic Polyelectrolytes: A New Look at Their Possible Roles as Opsonins, as Stimulators of Respiratory Burst in Leukocytes, in Bacteriolysis, And as Modulators of Immune-Complex Diseases: A Review Hypothesis. Inflammation, 11, 489-515. https://doi.org/10.1007/BF00915991

[10] Ginsburg, I., Sela, M.N., Morag, A., Ravid, Z., Duchan, Z., Ferne, M., et al. (1981) Role of Leukocyte Factors and Cationic Polyelectrolytes in Phagocytosis of Group a Streptococci and Candida albicans by Neutrophils, Macrophages, Fibroblasts and Epithelial Cells. Inflammation, 5, 289-312. https://doi.org/10.1007/BF00911094

[11] Hubner, G., Voigt, W., Schlumberger, H. and Ginsburg, I. (1985) Poly-L-Arginine Opsonizes Nuclei for Phagocytosis by Mouse Fibroblasts. IRCS Medical Science Biochemistry, 13, 934-935.

[12] Ginsburg, I. and Ram, M. (1960) Action of Antibodies and Plasmin on Ehrlich Ascites Tumour Cells. Nature, 185, 328-330. https://doi.org/10.1038/185328b0

[13] Ginsburg, I. (1959) Action of Streptococcal Haemolysins and Proteolytic Enzymes on Ehrlich Ascites Tumour Cells. British Journal of Experimental Pathology, 40, 417.

[14] Baird, B.R., Cheronis, J.C., Sandhaus, R.A., Berger, E.M., White, C.W. and Repine, J.E. (1986) O2 Metabolites and Neutrophil Elastase Synergistically Cause Edematous Injury in Isolated Rat Lungs. Journal of Applied Physiology, 61, 2224-2229. https://doi.org/10.1152/jappl.1986.61.6.2224 
[15] Henson, P. and Johnston, R. (1987) Tissue Injury in Inflammation. Oxidants, Proteinases, and Cationic Proteins. The Journal of Clinical Investigation, 79, 669-674. https://doi.org/10.1172/JCI112869

[16] Lichtenstein, A.K., Ganz, T., Selsted, M.E. and Lehrer, R.I. (1988) Synergistic Cytolysis Mediated by Hydrogen Peroxide Combined with Peptide Defensins. Cellular Immunology, 114, 104-116. https://doi.org/10.1016/0008-8749(88)90258-4

[17] Rodell, T., Cheronis, J. and Repine, J. (1988) Endothelial Cell Xanthine Oxidase-Derived Toxic Oxygen Metabolites Contribute to Acute Lung Injury from Neutrophil Elastase. Chest, 93, 146S. https://doi.org/10.1378/chest.93.3 Supplement.146S

[18] Ginsburg, I., Ward, P.A. and Varani, J. (1989) Lysophosphatides Enhance Superoxide Responses of Stimulated Human Neutrophils. Inflammation, 13, 163-174. https://doi.org/10.1007/BF00924787

[19] Varani, J., Ginsburg, I., Schuger, L., Gibbs, D., Bromberg, J., Johnson, K., et al. (1989) Endothelial Cell Killing by Neutrophils. Synergistic Interaction of Oxygen Products and Proteases. The American Journal of Pathology, 135, 435.

[20] Ginsburg, I., Gibbs, D.F., Schuger, L., Johnson, K.J., Ryan, U.S., Ward, P.A., et al. (1989) Vascular Endothelial Cell Killing by Combinations of Membrane-Active Agents and Hydrogen Peroxide. Free Radical Biology and Medicine, 7, 369-376. https://doi.org/10.1016/0891-5849(89)90123-8

[21] Anderson, B.O., Brown, J.M. and Harken, A.H. (1991) Mechanisms of Neutrophil-Mediated Tissue Injury. Journal of Surgical Research, 51, 170-179. https://doi.org/10.1016/0022-4804(91)90090-9

[22] Lehr, H. and Arfors, K. (1994) Mechanisms of Tissue Damage by Leukocytes. Current Opinion in Hematology, 1, 92-99.

[23] Ginsburg, I. and Sadovnic, M. (1998) Gamma Globulin, Evan's Blue, Aprotinin A PLA2 Inhibitor, Tetracycline and Antioxidants Protect Epithelial Cells against Damage Induced by Synergism among Streptococcal Hemolysins, Oxidants and Proteinases: Relation to the Prevention of Post-Streptococcal Sequelae and Septic Shock. FEMS Immunology \& Medical Microbiology, 22, 247-256. https://doi.org/10.1111/j.1574-695X.1998.tb01213.x

[24] Dallegri, F. and Ottonello, L. (1997) Tissue Injury in Neutrophilic Inflammation. Inflammation Research, 46, 382-391. https://doi.org/10.1007/s000110050208

[25] Ginsburg, I., Korem, M., Koren, E. and Varani, J. (2019) Pro-Inflammatory Agents Released by Pathogens, Dying Host Cells, and Neutrophils Act Synergistically to Destroy Host Tissues: A Working Hypothesis. Journal of Inflammation Research, 12, 35. https://doi.org/10.2147/JIR.S190007

[26] Ginsburg, I., Misgav, R., Pinson, A., Varani, J., Ward, P. and Kohen, R. (1992) Synergism among Oxidants, Proteinases, Phospholipases, Microbial Hemolysins, Cationic Proteins, and Cytokines. Inflammation, 16, 519-538.

https://doi.org/10.1007/BF00918977

[27] Ginsburg, I., Mitra, R.S., Gibbs, D.F., Varani, J. and Kohen, R. (1993) Killing of Endothelial Cells and Release of Arachidonic Acid. Inflammation, 17, 295-319. https://doi.org/10.1007/BF00918992

[28] Ginsburg, I. and Kohen, R. (1995) Synergistic Effects among Oxidants, Membrane-Damaging Agents, Fatty Acids, Proteinases, and Xenobiotics: Killing of Epithelial Cells and Release of Arachidonic Acid. Inflammation, 19, 101-118. https://doi.org/10.1007/BF01534384

[29] Ginsburg, I., Koren, E. and Heerden, P. (2017) Tissue Damage in Post Infectious 
Sequelae Is Caused by Asynergism between Microbial and Neutrophils-Derived Agonists: A Concern for a Disregard for Already Published Data. Journal of Emerging and Rare Diseases, 1, 101. https://doi.org/10.31021/jer.20181101

[30] Kolaczkowska, E. and Kubes, P. (2013) Neutrophil Recruitment and Function in Health and Inflammation. Nature Reviews Immunology, 13, 159-175. https://doi.org/10.1038/nri3399

[31] Wecke, J., Lahav, M., Ginsburg, I. and Giesbrecht, P. (1982) Cell Wall Degradation of Staphylococcus aureus by Lysozyme. Archives of Microbiology, 131, 116-123. https://doi.org/10.1007/BF01053992

[32] Ginsburg, I. (2002) The Role of Bacteriolysis in the Pathophysiology of Inflammation, Infection and Post-Infectious Sequelae. Apmis, 110, 753-770. https://doi.org/10.1034/j.1600-0463.2002.1101101.x

[33] Ginsburg, I. (2002) Role of Lipoteichoic Acid in Infection and Inflammation. The Lancet Infectious Diseases, 2, 171-179. https://doi.org/10.1016/S1473-3099(02)00226-8

[34] Cromartie, W.J., Craddock, J.G., Schwab, J.H., Anderle, S. and Yang, C.-H. (1977) Arthritis in Rats after Systemic Injection of Streptococcal Cells or Cell Walls. The Journal of Experimental Medicine, 146, 1585-1602. https://doi.org/10.1084/jem.146.6.1585

[35] Dalldorf, F.G., Cromartie, W.J., Anderle, S.K., Clark, R.L. and Schwab, J.H. (1980) The Relation of Experimental Arthritis to the Distribution of Streptococcal Cell Wall Fragments. The American Journal of Pathology, 100, 383.

[36] Fox, A., Schwab, J. and Cochran, T. (1980) Muramic Acid Detection in Mammalian Tissues by Gas-Liquid Chromatography-Mass Spectrometry. Infection and Immunity, 29, 526-531.

[37] Lourenco, E.V. and Cava, A.L. (2009) Cytokines in Systemic Lupus Erythematosus. Current Molecular Medicine, 9, 242-254. https://doi.org/10.2174/156652409787847263

[38] Ginsburg, I., Ward, P.A. and Varani, J. (1999) Can We Learn from the Pathogenetic Strategies of Group A Hemolytic Streptococci How Tissues Are Injured and Organs Fail in Post-Infectious and Inflammatory Sequelae? FEMS Immunology \& Medical Microbiology, 25, 325-338. https://doi.org/10.1111/j.1574-695X.1999.tb01357.x

[39] Wildhagen, K.C., García de Frutos, P., Reutelingsperger, C.P., Schrijver, R., Aresté, C., Ortega-Gómez, A., et al. (2014) Nonanticoagulant Heparin Prevents Histone-Mediated Cytotoxicity in Vitro and Improves Survival in Sepsis. Blood: The Journal of the American Society of Hematology, 123, 1098-1101.

https://doi.org/10.1182/blood-2013-07-514984

[40] Van Bruggen, M.C., Walgreen, B., Rijke, T.P., Corsius, M.J., Assmann, K.J., Smeenk, R.J., et al. (1996) Heparin and Heparinoids Prevent the Binding of Immune Complexes Containing Nucleosomal Antigens to the GBM and Delay Nephritis in MRL/LPR Mice. Kidney International, 50, 1555-1564. https://doi.org/10.1038/ki.1996.471

[41] Warren, J., Ward, P., Johnson, K. and Ginsburg, I. (1987) Modulation of Acute Immune Complex-Mediated Tissue Injury by the Presence of Polyionic Substances. The American Journal of Pathology, 128, 67.

[42] Ginsburg, I. (1999) Multi-Drug Strategies Are Necessary to Inhibit the Synergistic Mechanism Causing Tissue Damage and Organ Failure in Post Infectious Sequelae. Inflammopharmacology, 7, 207-217. https://doi.org/10.1007/s10787-999-0004-1 
[43] Robak, E. and Robak, T. (2012) Novel and Emerging Drugs for Systemic Lupus Erythematosus: Mechanism of Action and Therapeutic Activity. Current Medicinal Chemistry, 19, 438-453. https://doi.org/10.2174/092986712803414312

\author{
Abbreviations \\ systemic lupus erythematosus (SLE) \\ poly morpho nuclear phagocytes (PMNs) \\ nonsteroidal anti-inflammatory drugs (NSAIDs) \\ Hydroxychloroquine (HCQ) \\ azathioprine (AZA) \\ mycophenolate mofetil (MMF) \\ cyclophosphamide (CYC) \\ central nervous system (CNS) \\ B-lymphocyte stimulator (BLyS)
}

